\title{
Method and Case Study of Multiobjective Optimization-Based Energy System Design to Minimize the Primary Energy Use and Initial Investment Cost
}

\section{Dong-Seok Kong ${ }^{\text {, }}$ Yong-Sung Jang ${ }^{2}$ and Jung-Ho Huh ${ }^{1, *}$}

1 Department of Architectural Engineering, University of Seoul, Seoul 130-743, Korea; E-Mail: br011503@naver.com

2 GS E \& C Research Institute, GS Engineering \& Construction Corp, Seoul 449-831, Korea; E-Mail: ysjang02@gsconst.co.kr

* Author to whom correspondence should be addressed; E-Mail: huhj0715@uos.ac.kr; Tel.: +82-02-6490-2757; Fax: +82-02-6490-2479.

Academic Editor: Chi-Ming Lai

Received: 9 February 2015 / Accepted: 12 June 2015 / Published: 19 June 2015

\begin{abstract}
This study aimed to develop a building energy system design method to minimize the initial investment cost and primary energy use. As for the energy system, various combinations were generated depending on the type and capacity of the device used as well as the number of units, energy consumption, and efficiency of the building. Because the design process of energy systems is a critical step in determining the performance of the building throughout the lifecycle, an effective design method is necessary. The proposed method determines the energy system that can minimize the primary energy use and initial investment cost through a multiobjective optimization by calculating the cooling and heating energy consumptions of the building and initial investment cost of the energy system using the load profile by the design-day, and the information in the design phase of the building. This method can support the decision-making process by providing engineers with an alternative proposal for minimizing the initial investment cost and primary energy use by the Pareto analysis after reviewing the design combinations of various energy systems with limited information in the initial design phase. To verify the effectiveness of the methodology, a case study of the two buildings was performed, and the analysis results were compared to the conventional design alternatives. As shown in the case study results, using a method developed in comparison with the conventional result can provide the efficient alternative selection with $80 \%$ of initial investment cost and $86 \%$ of primary energy use, respectively.
\end{abstract}


The results confirmed that the proposed methodology can provide various optimum results more effectively compared to the conventional design methods.

Keywords: energy system design; multiobjective optimization; initial investment cost; primary energy use

\section{Introduction}

The energy system of a building can yield a variety of combinations depending on the types and capacities of the devices used as well as the number of units and the energy consumption. Moreover the efficiency of a building during its lifecycle is determined by various combinations of the devices. The energy system design process is a critical step in determining the performance of a building throughout its lifecycle. As such, the analysis of a building's energy consumption and cost by reviewing various design alternatives is necessary to devise a design meeting the needs of the users by providing them with a number of alternatives. However, in most of the cases, business constraints such as lack of time for review, lack of design information, institutional restrictions, and client requirements fail to investigate various design combinations. For this reason, the conventional designs have been dependent on the ability of the experts to review a small number of design alternatives. This tends to oversize [1] and has a significant adverse effect on the energy performance and initial investment cost of the building. In particular, the energy performance of a building has the largest potential effect on the efforts in the early stage of the design process [2], and a big difference in the energy performance occurs depending on the type of HVAC\&R system used [3]. Therefore, the judgment in the design process is most important in terms of economy and energy. In the case of the energy system, it is difficult to change and retrofit because its replacement cycle of more than 20 years [4] requires a more prudent decision.

Moreover, because of the recent issue of the lack of energy and building energy savings, there has been an increasing number of studies on the combined use of energy-saving devices such as the renewable-energy systems, high-performance devices, geothermal heat pump, ice thermal storage system, water thermal storage system, and absorption chiller and heater, and conventional devices including the turbo refrigerator (TR), gas boiler, and absorption refrigerator. However, these devices have different mechanical characteristics (performance curves) [5], and a vast number of design combinations are possible based on the sizing of the energy system. Therefore, the studies must be accompanied by a review of various design combinations by the optimization. Few studies have been reported on these cases. Using a genetic algorithm, Kayo et al. [5,6] investigated the energy system to minimize the waste heat of the cogeneration system. Considering the systems operation, Ooka et al. [7] optimized capacities of the five systems of TR, AR, EHP, GB, and CGS. Through optimization study, Seo et al. [8] also determined system configuration and capacity with minimum primary energy demand and Shaneb et al. [9] solved the sizing problem of CHP. These studies have shown that it is able to effectively determine the amount of energy systems through the optimization. However, these studies could not reflect the equipment such as GSHP and ACH required for the efficient building design and there has been a limit to the use of a system that can reduce the maximum system capacity such as ITS. This part is big different from the previous studies. In addition, in the present study, it was optimized to 
reflect the user's requirements as constraints. This optimization method can be said to bring more realistic results. The determination of the energy system to be used in the design phase is affected by various factors such as the energy to be consumed, initial investment cost, environmental/operational costs, and lifecycle cost (LCC). Among these, the initial investment cost is one of the most important factors as it considers the limits of the construction costs. Harris et al. [10] conducted a research on the investment for the energy performance of buildings. Eighty percent of all the respondents answered that payback period is the most significant factor to consider when investing. In other words, it is most important for them to obtain the greatest effect vis-à-vis the investment cost. In a study by Kayo and Ooka [11], the initial investment cost and energy consumption were used as indicators for the determination of the energy system to be used, and the studies by [12,13] applied the initial investment cost as an indicator for the optimal design of high-efficiency buildings, because it is an important factor for making decisions.

The previous studies that analyzed the application of energy systems in the early design stage focused on the sizing of the energy system rather than on the review of the device combination and performed restrictive analyses of the types and number of devices used. Moreover, a review of the case studies considering various constraints on the project characteristics is needed for the analysis of the applicability on an actual case. This study is different from other studies in that the applicability was investigated with a focus on the analysis of actual cases. In this regard, this study aimed to develop an energy system design method based on the restrictive information in the early stage of the design process by the identification of the constraints and problems in the design process, by reviewing the conventional design approaches for building energy systems and the conventional energy consumption analysis methods. The proposed method presents the best alternative by analyzing the combinations of various devices and can provide the optimum energy system design alternatives based on the primary energy use and initial investment cost calculation results depending on the types and capacities of the devices used. The optimization was conducted using the nondominated sorting genetic algorithm (NSGAII) [14,15], a multi-objective optimization algorithm, and the best alternative was provided using the Pareto analysis method. Moreover, the proposed method was compared to the conventional methods by the analysis of the two design cases.

\section{Limitations of the Conventional Energy System Design Process}

According to the literature [16,17], the design process of the conventional energy systems consists of the following four stages:

(1) Building heating/cooling load calculation: The peak heating and cooling load calculation methods such as cooling load temperature differential (CLTD) method and radiant time series method (RTS) [18] were used, and the heating and cooling load profile by the design-day is calculated using these methods.

(2) Device type selection: The type of device used is determined according to the purpose and characteristics of the building. In this process, engineers select the device type that meets the client requirements and institutional design criteria. For example, clients may want devices such as the geothermal heat pump and water thermal storage system, and heating and cooling systems using district heating should be designed in a specific administrative area. In this case, the absorption chiller and heater or absorption refrigerator can be selected as the device to be used. Furthermore, South Korea has an 
institutional regulation that requires buildings with a total floor area exceeding $5000 \mathrm{~m}^{2}$ to adapt a nonelectrical energy system that must use more than $60 \%$ of the peak cooling load, or to use the thermal storage system. Therefore, most of South Korea's building energy systems consist of many different devices, posing a very complex problem from the point of view of the design aspects.

(3) Device capacity determination: The capacity to withstand the peak heating and cooling loads calculated by the developed process [1] is determined. The safety factor is taken into account in certain cases.

(4) Energy system performance analysis: The efficiency and energy consumption of the planned energy system is analyzed. In this process, options for saving energy such as using a renewable-energy system and control system are reviewed along with economic-feasibility analysis.

Through the energy system design process, designers are required to provide a proper alternative proposal. The process of determining the type and capacity of the device to be used, however, depends on the judgment of experts and device information from the manufacturers in most of the cases. In the research conducted by Jacobs et al. [2], 47\% of the survey respondents rely on the device information from the manufacturer and $14 \%$ selected based on their past experiences. However, this method has a limitation, because reviewing the combinations of various devices depends solely on the experience and judgment of experts. In particular, in the case with a demand for multiple device types, as in Figure 1, a systematic review method is needed.

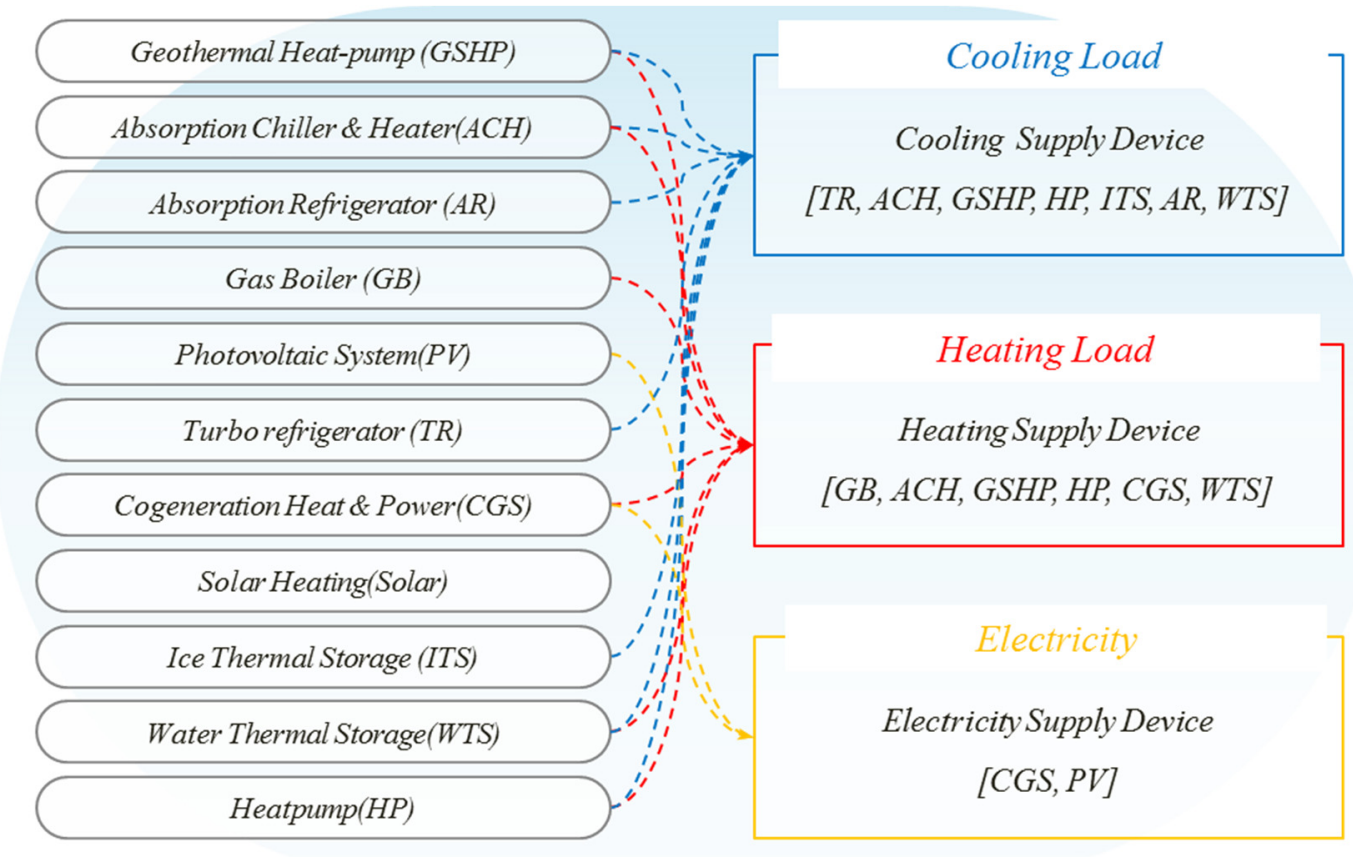

Figure 1. Various device types for the building energy system.

Energy system design is a method of calculating the peak heating and cooling loads of buildings and is different from the load calculation method for the building energy consumption. In the research conducted by [2], 31\% of the survey respondents analyzed the energy savings of buildings based on past experience, $26 \%$ in accordance with the existing guidelines, and $20 \%$ from the device information from the manufacturer, indicating that in most of the cases, a precise analysis was not performed. This can have an adverse effect on the energy consumption of buildings in the long term. The research findings reveal that there is a difference of up to $30 \%$ in buildings' energy consumption depending on the 
characteristics of the building energy system used [19], and therefore, it is very important to analyze the building energy consumption in the design process. In this study, the building energy consumption was calculated using the energy analysis method based on the performance curve that represents the characteristics of the device used in the literature [5-7]. The calculation of the building energy consumption is based on the design information such as the heating and cooling design-days.

\section{Multiobjective Optimization Method}

\subsection{Method}

The method proposed in this study was aimed at providing the optimal alternatives by investigating various device combinations that can be applied to the design of building energy systems using the optimization algorithms. Designers or engineers design energy systems considering various indicators such as the initial investment cost, energy performance, LCC, and carbon emission. Moreover, the investment cost for the construction of a building and the building's energy consumption during its operating hours are considered as the most important indicators. Thus, a design that can minimize these two indicators can be an important and reasonable alternative in the decision-making process. The high-efficiency devices consume low energy, but pose the disadvantage of a higher investment cost, whereas the devices that utilize low investment cost trigger larger energy consumption. Therefore, a method that considers these two indicators at the same time is required. The proposed method was designed to provide a number of optimal solutions using the multiobjective optimization. The method using NSGAII, a multiobjective optimization method, based on a genetic algorithm can offer effective optimal solutions, and its effectiveness has been verified [20,21]. Hamdy [22] drew nearly-zero-energy building solutions to minimize the cost and energy using the NSGAII and Gossard carried out the study to optimize the thermal performance of outside wall for minimization of building energy consumption and thermal comfort. These results implies that the algorithm is suitable for multi-NAGSII optimized.

Figure 2 shows a schematic diagram of the method proposed in this study. The energy consumption and initial investment cost were calculated using the type and capacity of the device, listed in Table 1, as the variables. The energy system design has limited available information, as mentioned in Section 2, and focuses on the peak load calculation. Therefore, the energy consumption is calculated based on the profile of the representative dates included in the heating and cooling periods and the interim period, and the investment cost was calculated using the initial investment cost model created by the function of the capacity of the device used. The initial investment cost and energy consumption were applied as the objective functions for the optimization, and the user's requirements and institutional particulars were reflected as the constraints for the optimization. All these processes were performed based on the function coded in the MATLAB platform. The alternatives evaluated by the multiobjective optimization algorithm provided a number of optimal solutions using the Pareto analysis, and these solutions were utilized as alternatives in the decision-making process. 


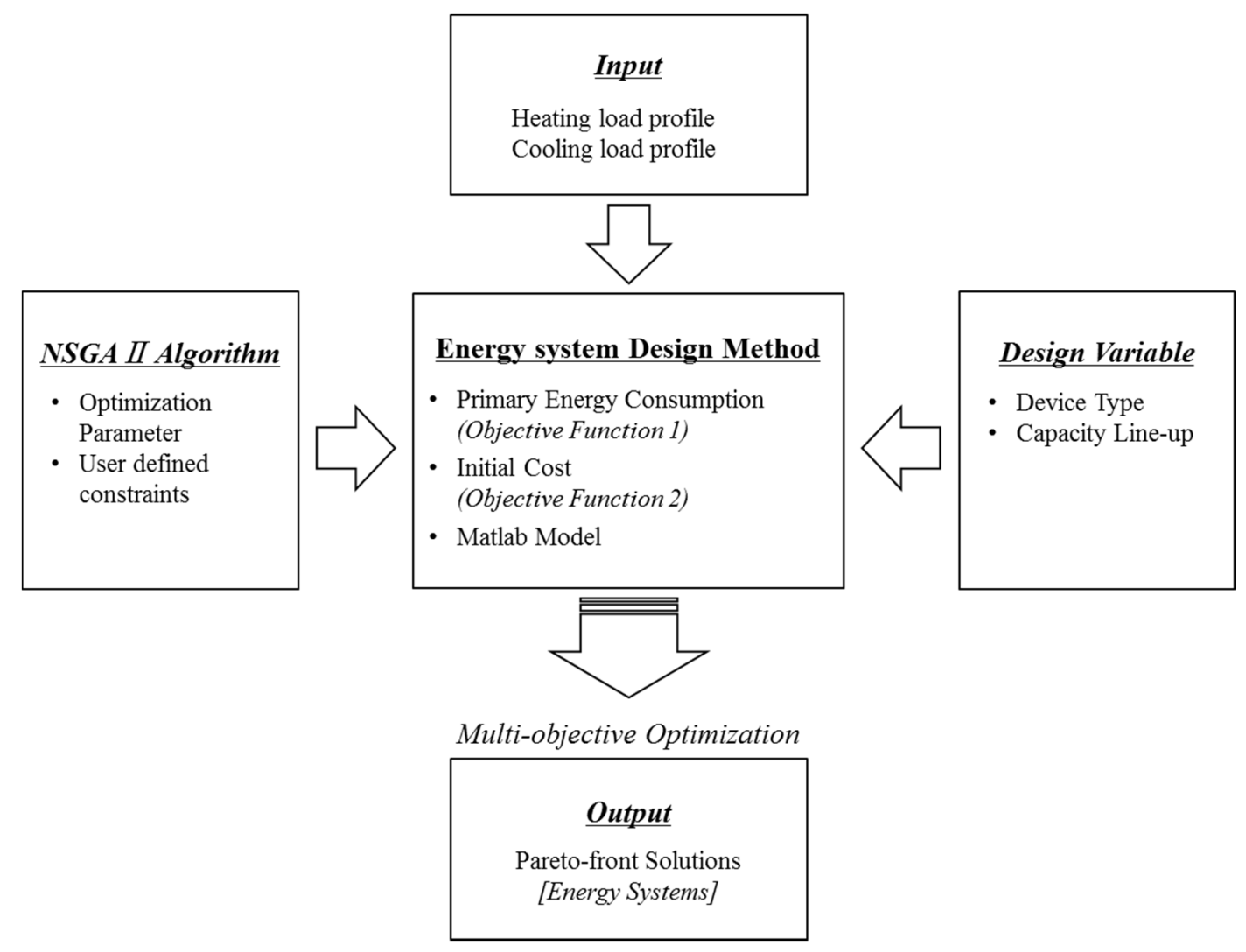

Figure 2. Schematic diagram of the optimization method.

Table 1. Device type and capacity line-up for building energy system design.

\begin{tabular}{cccccccccc}
\hline Type & Acronym & \multicolumn{8}{c}{ Capacity Line-Up of Device (kW)-Variable } \\
\hline Turbo refrigerator & TR & 0 & 390 & 470 & 630 & 680 & 780 & 945 & 1000 \\
Absorption refrigerator & AR & 0 & 95 & 125 & 160 & 320 & 380 & 560 & 630 \\
Absorption chiller \& heater & ACH & 0 & 95 & 125 & 160 & 320 & 380 & 560 & 630 \\
Heat pump & HP & 0 & 25 & 30 & 40 & 50 & 63 & 78 & 100 \\
Gas boiler & GB & 0 & 60 & 85 & 115 & 150 & 185 & 290 & 350 \\
Cogeneration system & CGS & 0 & 115 & 200 & 230 & 300 & 350 & 480 & 600 \\
Ice thermal storage & ITS & \multicolumn{7}{c}{ TR capacity $\times 10 \mathrm{~h} *$} \\
Water thermal storage & WTS & \multicolumn{7}{c}{ ACH or GSHP capacity $\times 10 \mathrm{~h} *$} & \\
Geothermal heat pump & GSHP & 0 & $10 \%$ & $20 \%$ & $30 \%$ & $40 \%$ & $50 \%$ & $60 \%$ & $70 \%$ \\
Photovoltaic system $\left(\mathrm{m}^{2}\right)$ & PV & 0 & 20 & 50 & 100 & 150 & 200 & 250 & 300 \\
Solar heating system $\left(\mathrm{m}^{2}\right)$ & Solar & 0 & 20 & 50 & 100 & 150 & 200 & 250 & 300 \\
\hline
\end{tabular}

Note: * ITS and WTS can be charged only 10 hours in korea.

The capacity of the devices used was subjected to change depending on the scale of the energy system and are listed in Table 1 based on the product line-up and catalogs of various devices. The TR and gas boiler (GB) were divided into four units for the analysis. Moreover, two units each of the absorption refrigerator (AR), heat pump (HP), and cogeneration system (CGS) were considered, and one unit was taken into account for each of the other devices. The capacity of the ice thermal storage system (ITS) was connected to that of the turbo generator and calculated by multiplying the capacity of the turbo generator to the midnight power service time. The water thermal storage system was used by connecting to the absorption chiller and heater $(\mathrm{ACH})$ or geothermal heat pump (GSHP), and its capacity was 
calculated by multiplying the capacity of the connected device to the heat storage time $(10 \mathrm{~h})$, as with the ITS. The capacity of the GSHP was set at 10\%-70\% of the cooling and heating peak loads to meet the standard that more than a certain portion of the peak heating and cooling loads should be applied with respect to renewable-energy sources in accordance with the South Korean institutions. The capacity of the device was treated as a discrete variable in the optimization algorithm. The variables of the optimization target are listed in Table 2. Each of the variables signifies the capacity of the targeted device.

Table 2. Variables for optimization.

\begin{tabular}{ccc}
\hline Device Type & No. of Device & Variables \\
\hline TR & 4 & $\sim \mathrm{x} 01-\mathrm{x} 04$ \\
AR & 2 & $\sim \mathrm{x} 05-\mathrm{x} 06$ \\
ACH & 1 & $\mathrm{x} 07$ \\
HP & 2 & $\sim \mathrm{x} 08-\mathrm{x} 09$ \\
GB & 4 & $\sim \mathrm{x} 10-\mathrm{x} 13$ \\
CGS & 2 & $\sim \mathrm{x} 14-\mathrm{x} 15$ \\
ITS & 1 & $\mathrm{x} 04$ \\
WTS & 1 & $\mathrm{x} 07 \mathrm{or} 16$ \\
GSHP & 1 & $\mathrm{x} 16$ \\
PV & 1 & $\mathrm{x} 17$ \\
Solar & 1 & $\mathrm{x} 18$ \\
\hline
\end{tabular}

\subsection{Objective Function (1): Primary Energy Use}

In this study, the methodology proposed by Ooka et al. [5-7] was adapted as the method for calculating the energy consumption. This method was used to determine the capacity of the energy system considering the supply aspects and mechanical characteristics of the device used. The primary energy use by the energy system is expressed by Equation (1):

$$
E_{\text {system }}=\sum_{d=1}^{3} \sum_{i=1}^{24} \frac{Q_{\text {needs }, d, i}}{\eta}
$$

The energy consumption of the system $\left(E_{\text {system }}\right)$ was calculated by dividing the heating and cooling needs of the building $\left(Q_{\text {needs,d,i }}\right)$ by the efficiency of the device used $(\eta)$ and then converted into the annual energy consumption if added up hourly (i) and daily (d). However, $\eta$ varies depending on the partial load ratio (PLR). The PLR is shown Equation (2) with respect to the building needs $\left(Q_{\text {needs,d,i }}\right)$ and rated output of the device used ( $\left.Q_{\text {device,rated }}\right)$ [23]. The performance of the device used can be represented by a quadratic or cubic equation, and in the case of a cubic equation, it is shown in Equation (3):

$$
\begin{gathered}
P L R_{d, i}=\frac{Q_{\text {needs }, d, i}}{Q_{\text {device,rated }}} \\
\eta=C_{1}+C_{2} \cdot P L R+C_{3} \cdot P L R^{2}+C_{4} \cdot P L R^{3}
\end{gathered}
$$

The efficiency of the device used changes according to the PLR and can be defined as a unique pattern depending on the device type referred as the performance curve. In this study, the mechanical characteristics of the devices listed in Table 1 were defined based on the performance curve. Figure 3 shows the performance curve according to the characteristics of the devices used in this study. 


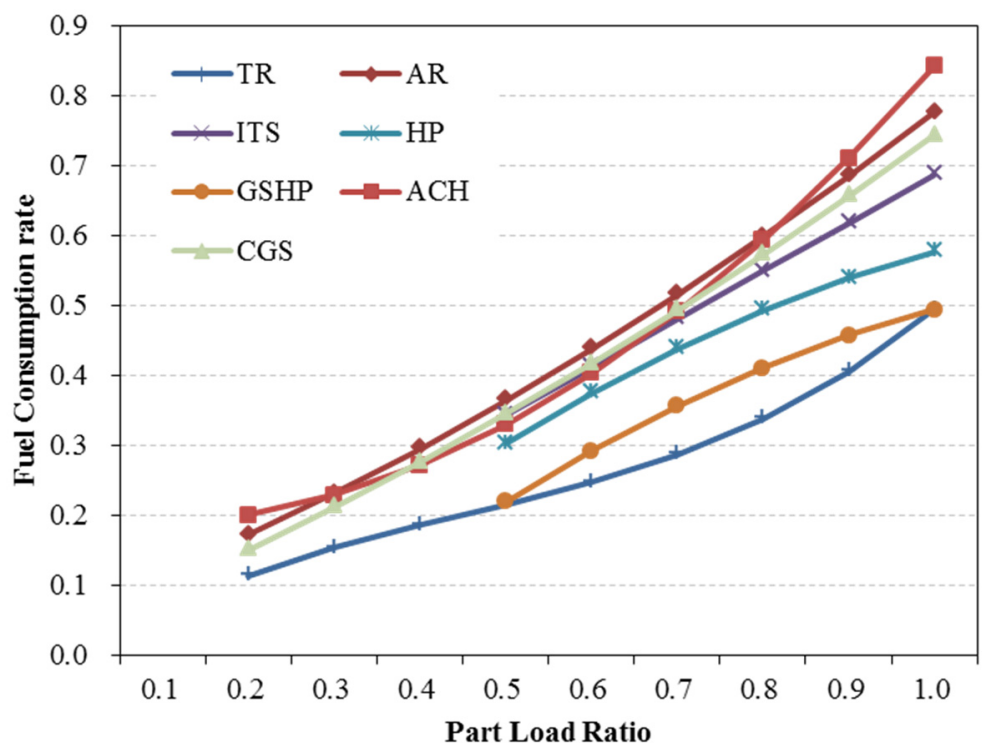

Figure 3. PLR device curve (example).

This pattern was obtained by the performance data from the manufacturers by device type and created using the information collected based on the manufacturers' product catalog data. The building heating and cooling loads required for calculating the building energy consumption used the three-day heating and cooling load profiles by the design-day (January: heating; April: cooling mid-season; August: cooling) created for calculating the device capacity. The energy system of the building operates the device in response to the building heating and cooling loads, and the PLR occur in this process. However, in the case with more than two devices, various PLR combinations were utilized. To review these combinations, the PLR of each device was defined as 0 to 1 at the 0.25 unit. PLR were tested in increments of 0.25 units. For the PLR stage, four stages, the minimum standards for the efficient design of HVAC, were applied [17]. For example, if there were three refrigerators with a cooling load of $100 \mathrm{kWh}$, the energy consumption of the device combination was $100 \mathrm{~kW}$ at $i$ hour; various operating combinations were utilized such as operating one refrigerator up to $100 \%$, operating two refrigerators by $50 \%$ each, and operating three refrigerators by $25 \%, 25 \%$, and $50 \%$ with respect to the PLR of the devices at $i$ hour. The proposed method was programmed to investigate all the possible combinations that occur as the PLR of all the devices used varying from $25 \%$ to $100 \%$, and this subsequently helped in the selection of the PLR combination with the minimum energy use. This is for reviewing the best device combination under the assumption that the energy system will be operated at its optimal condition. This process was performed for $72 \mathrm{~h}$ or three days in January, April, and August. As the energy sources consumptions differed according to the type of device used, the total energy consumption was converted into primary energy use for the integration purposes. The primary energy conversion factors based on the South Korean standards are listed in Table 3.

Table 3. Primary energy factors in Korea [24].

\begin{tabular}{cc}
\hline Energy Source & Primary Energy Factor \\
\hline Gas & 1.1 \\
Electricity & 2.75 \\
District heating & 0.614 \\
District cooling & 0.937 \\
\hline
\end{tabular}




\subsection{Objective Function (2): Initial Investment Cost}

The initial investment cost of the energy system $\left(C_{\text {initial }}\right)$ was defined as a function of the rated capacity $\left(Q_{\text {device,rated }}\right)$ by type of device used, and it is represented using Equation (4):

$$
C_{\text {initial }}=\alpha+\beta \cdot e^{-Q_{\text {device,rated }}}
$$

The function of the initial investment cost was created with a regression model using the survey data, database (DB) of Korea Price Information Center [25], and initial investment cost ( $y$-axis) based on the capacity of the device used ( $x$-axis) as an exponential function. The investment-cost model was created by fitting the function defined in Equation (4) to the survey data. Figure 4 shows the fitting results of the initial investment model and survey data.

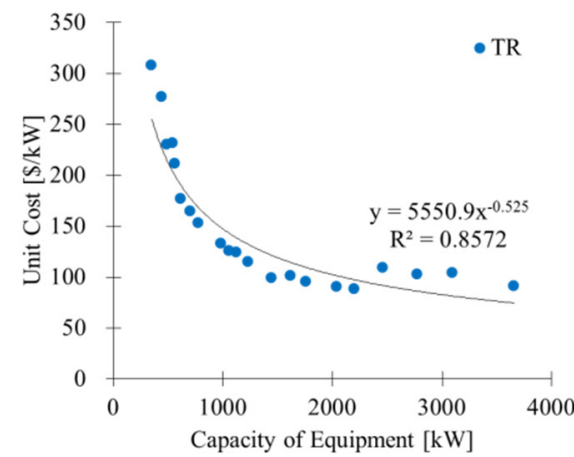

(a)

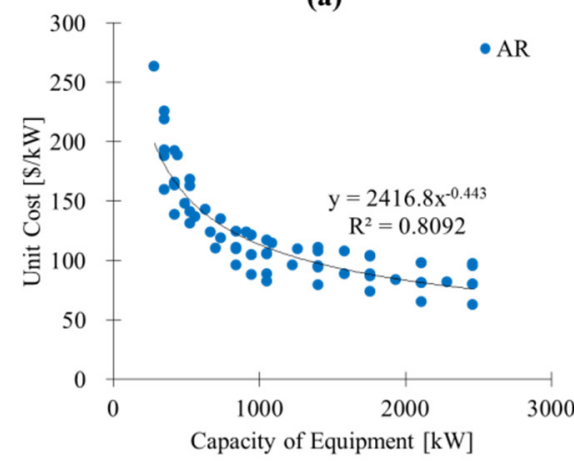

(d)

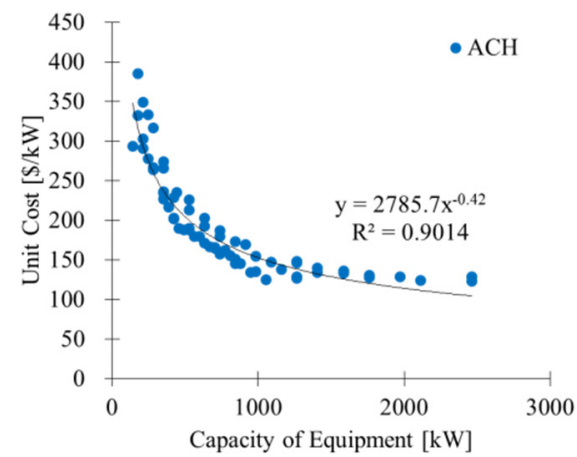

(b)

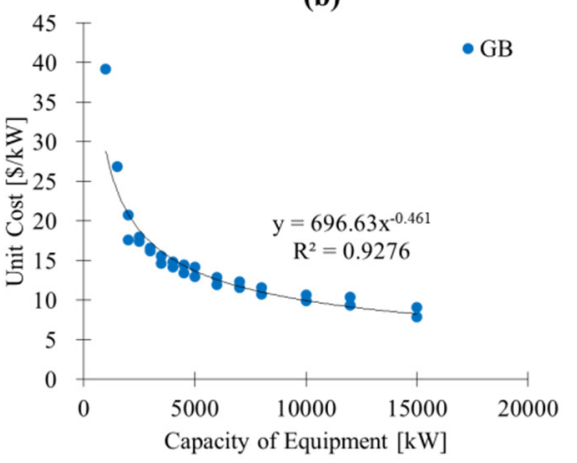

(e)

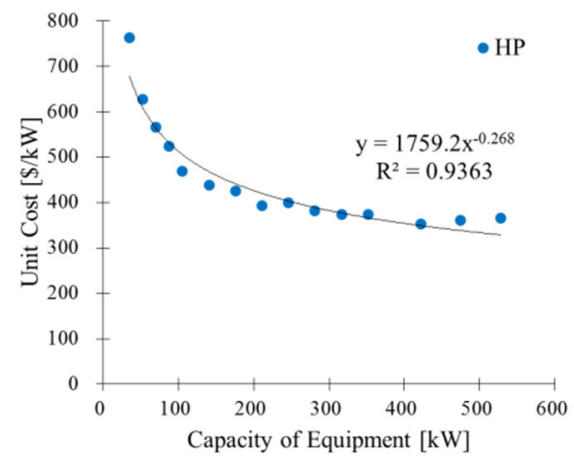

(c)

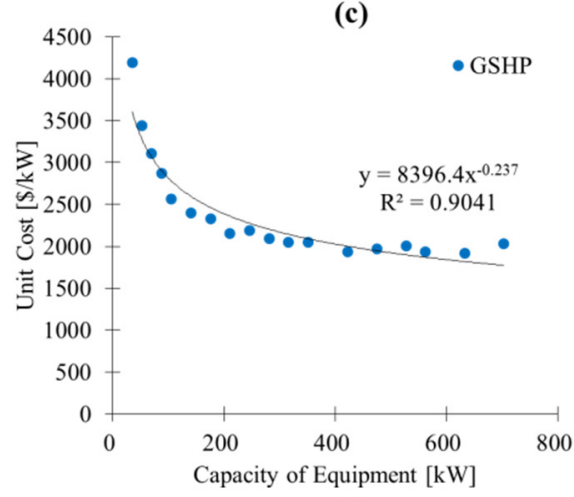

(f)

Figure 4. Curve fitting result of the initial investment cost model. (a) Turbo refrigerator;

(b) Absorption Chiller \& Heater; (c) Heatpump; (d) Absorption Refrigerator; (e) Gas Boiler;

(f) Geothermal Heatpump.

Figure 5 shows the initial investment cost of the device used with respect to the capacity as listed in Table 1. The investment cost model of each device revealed that when a device with a larger capacity was applied, the investment cost per unit capacity became smaller, and the division of the device into units with smaller capacities increased initial investment cost. In the case of the investment cost model, if the underlying data was changed depending on the survey year and inflation rate, continuous data updating was needed. 


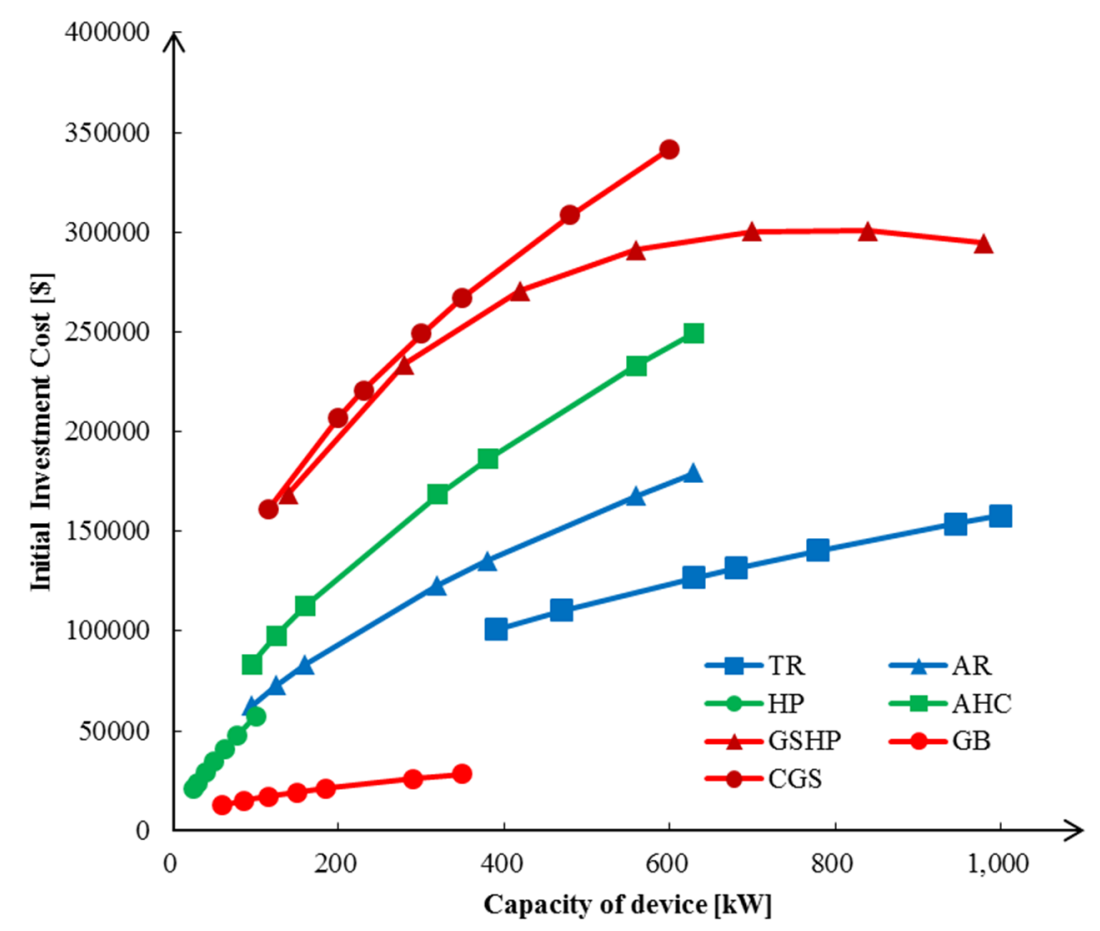

Figure 5. Initial cost model for the building energy system.

\subsection{Constraints}

The constraints were identified as the minimum capacity of the energy system, user's requirements, and mandatory energy system design regulations. Thus, they were subjected to change according to the design case. The condition of the minimum capacity of the energy system was included in the common factors. The minimum capacity was determined to be $110 \%$ of the heating and cooling loads considering the safety factor in the general design. The safety factor considers the heating and cooling load deficiency in the energy system design and is known to be $110 \%-140 \%$ depending on the engineer and designer [1]. However, as oversizing significantly decreases the efficiency of the energy system [26], the capacity was defined as $110 \%$ to prevent oversizing. In addition to these, the mandatory use of renewable-energy sources, application of the thermal storage system, and institutional requirements were the inputs for each case, according to the user's characteristics.

\subsection{Pareto Analysis}

The results of this study were obtained by the Pareto analysis. The basic concept of Pareto analysis is 'nondomination'. As shown in Figure 6, in the case with two solutions such as A and B, B has a better value than $A$ with respect to the indicators of the initial investment cost and primary energy use when $B$ dominates A. In the case of B and C, B has less primary energy use but a higher initial investment cost compared to $\mathrm{C}$, whereas $\mathrm{C}$ has more primary energy use, but a lower initial investment cost compared to $\mathrm{B}$. Therefore, it is difficult to select a better alternative between the two solutions such as B and C with regard to the primary energy use and initial investment cost, and the two solutions are said to be in a nondominant relationship. These two solutions are the potential optimal solutions, and the line connecting these nondominant solutions was named as the 'Pareto front'. The multiobjective optimization algorithm based on the Pareto front aimed to find a set of Pareto optimal solutions. The Pareto analysis technique 
is largely used in the decision-making models, because the users can select various optimized solutions using this analysis.

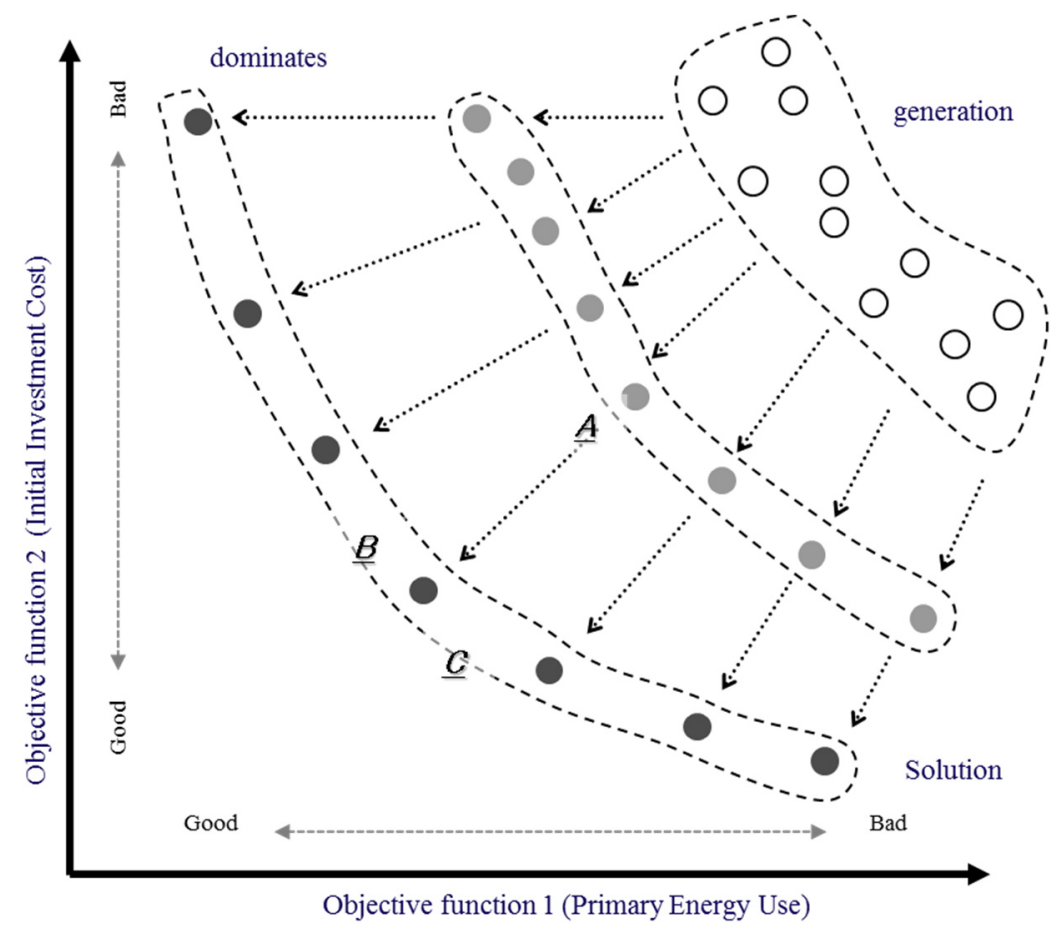

Figure 6. Concept of the pareto optimal solution.

In Section 4, the applicability of the optimal design methodology determined via a case analysis of the two actual designs was verified in the connection with the optimization on the energy use and initial investment cost of the energy system explained in Section 3.

\section{Case Studies}

\subsection{Building 1}

A newly constructed 21-story commercial building, Building1, was designed with an energy system based on the peak cooling and peak heating loads of 5693 and $4962 \mathrm{~kW}$, respectively. Weather conditions of the target area for the design load calculation were calculated based on the maximum temperature of $31.6{ }^{\circ} \mathrm{C}$, the minimum temperature of $-8.4{ }^{\circ} \mathrm{C}$, space cooling of $26{ }^{\circ} \mathrm{C}$, and space heating of $20{ }^{\circ} \mathrm{C}$. As the thermal characteristics of building envelope, the outside wall is $0.141\left(\mathrm{~W} / \mathrm{m}^{2} \cdot \mathrm{k}\right)$; the lowest floor of $0.14\left(\mathrm{~W} / \mathrm{m}^{2} \cdot \mathrm{k}\right)$; the windows are $1.07\left(\mathrm{~W} / \mathrm{m}^{2} \cdot \mathrm{k}\right)$. Total floor area is $139,940 \mathrm{~m}^{2}$. On the basis of the occupied office building, internal heat loads are occupants of 0.1 (person/ $\left.\mathrm{m}^{2}\right)$, lighting density of $7\left(\mathrm{~W} / \mathrm{m}^{2}\right.$ ) and equipment density of $21\left(\mathrm{~W} / \mathrm{m}^{2}\right)$. The energy system of the original design alternative was provided with district heating of medium-temperature water, heating supply by a heat exchanger, and cooling supply by an absorption chiller, and it had an installed GSHP covering $40 \%$ of the peak cooling load. Figure 7a shows the diagram of the energy system of the original design alternative. Figure 8a shows the cooling and heating load profiles of the target building. The primary energy use of the energy system designed with the conventional methods turned out to be $32,000 \mathrm{kWh}$ ( 3 days), and the initial investment cost was US\$3,188,937. 
In the design of the building energy system, ensuring technology and cost competitiveness are considered as the important issues. Energy systems such as GSHP are energy-efficient, but pose the burden of an increase in the prime cost. Thus, it is important to investigate the combinations of various energy systems through the optimal design.

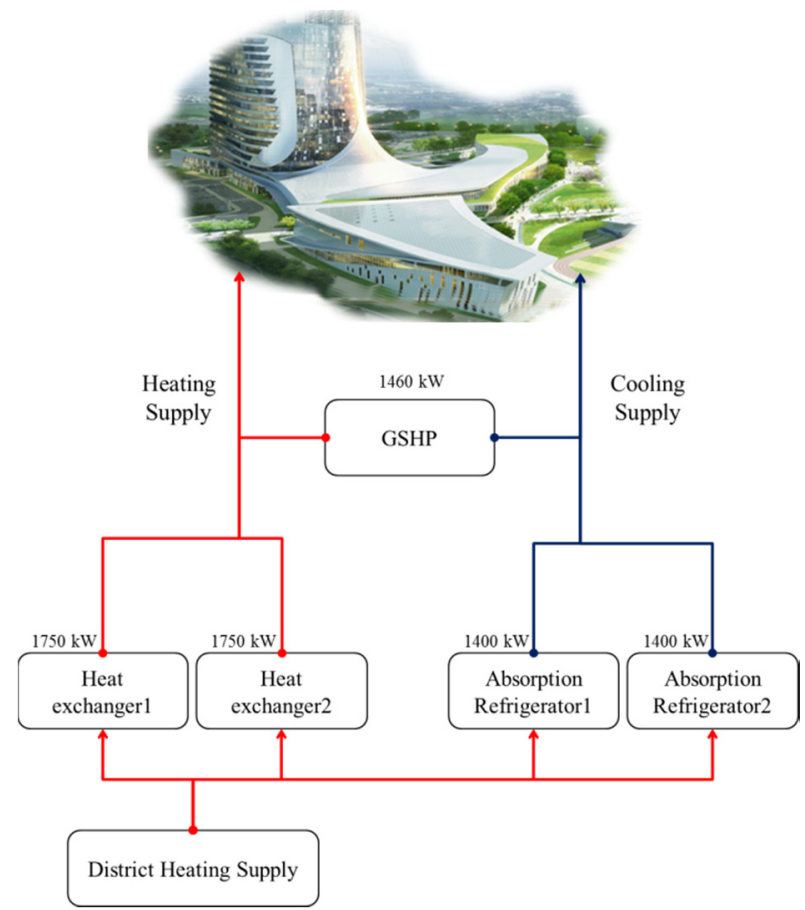

(a)

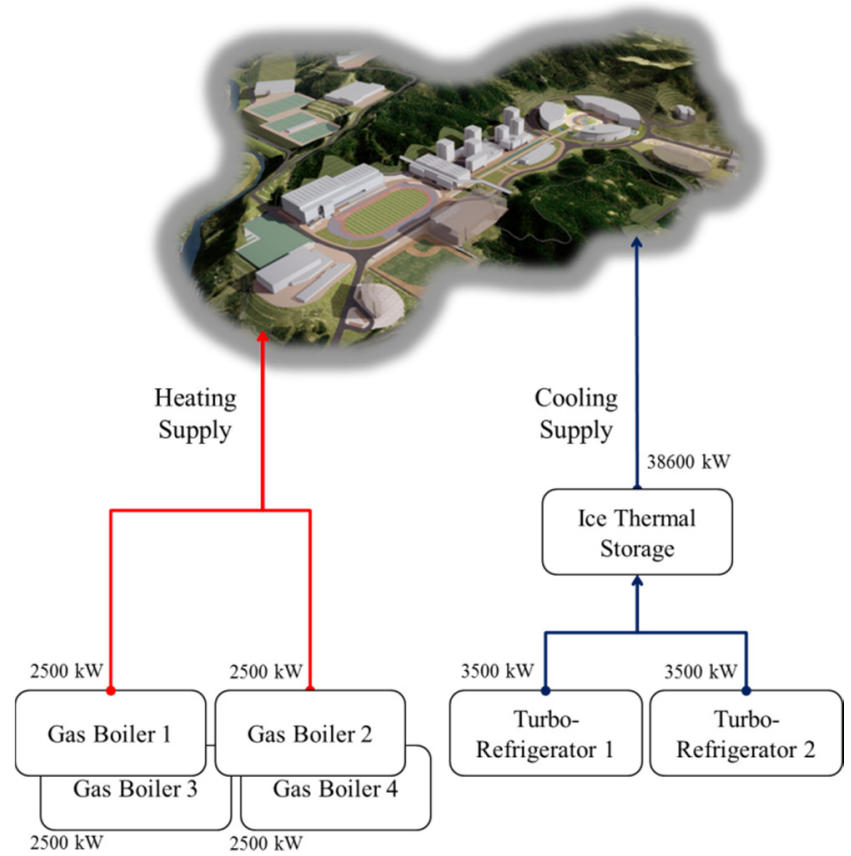

(b)

Figure 7. Energy system designs by an expert. (a) building 1; (b) building 2 .

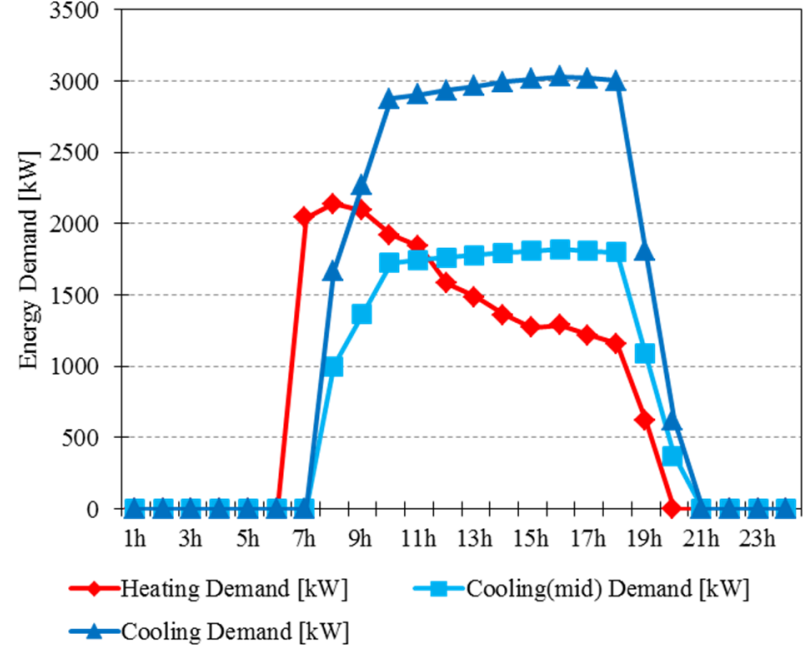

(a)

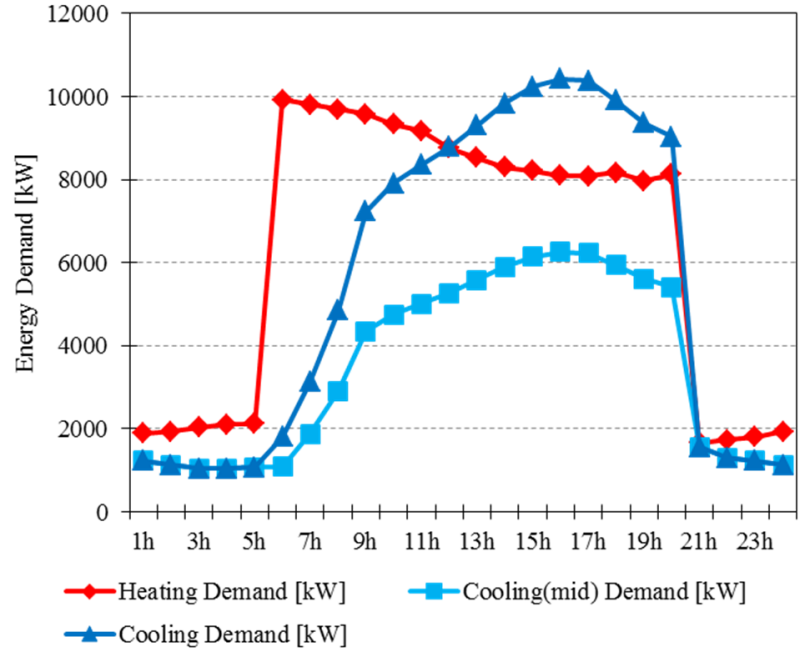

(b)

Figure 8. Load profiles of the case study buildings. (a) building 1; (b) building 2.

The design of the target building included a GSHP covering more than $40 \%$ of the peak cooling load. Accordingly, for Building 1, a comparative analysis of the case in which GSHP was applied by $40 \%$ under the same constraints as those of the original design alternative and the case exploring all the combinations randomly was performed. 


\subsection{Building 2}

Building 2 is a 15-story building spanning sports complex and business offices with a total floor area of $55,340 \mathrm{~m}^{2}$. As the climatic conditions of the area where this building is located, the highest temperature is $32.5{ }^{\circ} \mathrm{C}$; the minimum temperature is $-12.1{ }^{\circ} \mathrm{C}$; the room temperature is the same as building 1. As the thermal properties of building envelope, the outside wall is $0.37\left(\mathrm{~W} / \mathrm{m}^{2} \cdot \mathrm{k}\right)$; the ground floor is $0.24\left(\mathrm{~W} / \mathrm{m}^{2} \cdot \mathrm{k}\right)$; the windows are $1.59\left(\mathrm{~W} / \mathrm{m}^{2} \cdot \mathrm{k}\right)$. The building consists of offices and accommodations. Internal heat loads of offices are occupants of 0.2 (person $/ \mathrm{m}^{2}$ ), lighting density of $15\left(\mathrm{~W} / \mathrm{m}^{2}\right)$ and equipment density of $25\left(\mathrm{~W} / \mathrm{m}^{2}\right)$; internal heat loads of accommodations are occupants of $0.06\left(\right.$ person $\left./ \mathrm{m}^{2}\right)$, lighting density of $15\left(\mathrm{~W} / \mathrm{m}^{2}\right)$ and equipment density of $5\left(\mathrm{~W} / \mathrm{m}^{2}\right)$.

Its peak cooling and heating loads were 10,431 and $9917 \mathrm{~kW}$, respectively. The energy system, designed using the conventional method, was composed of a 38,600 kW ITS, two $3500 \mathrm{~kW}$ TRs, and four $2500 \mathrm{~kW}$ GBs. Figure $7 \mathrm{~b}$ shows the energy system of Building 2. Figure $8 \mathrm{~b}$ shows the heating and cooling load profiles by the design-day. The primary energy use of the conventional design alternative was $314,448 \mathrm{kWh}$, and the initial investment cost was determined to be US\$1,284,195.

As mentioned in Section 2, in South Korea, buildings over a certain size are required to be designed with a cooling system using gas or an ITS for more than $60 \%$ of the peak heating/cooling load, as a way of reducing the electrical demand. Accordingly, an analysis was performed with the case in which ITS was applied by $40 \%$ under the same conditions as that of the case of the original design alternative and the case withstanding $40 \%$ of the cooling load by mixing a nonelectric device with the ITS. Nonelectric devices included the AR, GSHP, ITS, and ACH. As the geothermal storage pump is considered a renewable-device in South Korea, it is regarded as a nonelectric device.

\section{Results and Discussion}

Figure 9 shows the optimal results of Building 1, which is the case where the GSHP covers $40 \%$ of the peak cooling load. In the figure, the base represents the energy system designed with the conventional method; the square point shows the optimal solution created by the optimization by applying the GSHP by $40 \%$; the triangle point shows the global optimal results deduced by the optimization without constraints; the circular dots show the reviewed individuals. The calculated initial investment costs, primary energy uses, and energy system configurations of the optimal solutions are listed in Table 4. Compared to the base, the result of the optimized energy system created a combination of devices that can implement diverse energy- and cost-saving methods. The optimization results provided primary energy use ranging from $86 \%$ to $107 \%$ and an initial investment cost of $80 \%-104 \%$. Combination (a) provided an alternative that increased the initial investment cost by $4 \%$, but decreased the energy consumption by $14 \%$ compared to the original alternative, and combinations (b)-(e) provided a design alternative with an advantage over the original alternative in terms of cost and energy. Therefore, they provided the results of the energy system that can help to achieve energy savings without increasing the initial investment cost. GSHP 40\% optimal solutions shows the selected value through the optimized to meet the design criteria of the target building. In Figure 9, 'random' represents the random result of optimization without constraints. This result means output that can be obtained through the optimization of the ideal state without constraint. 


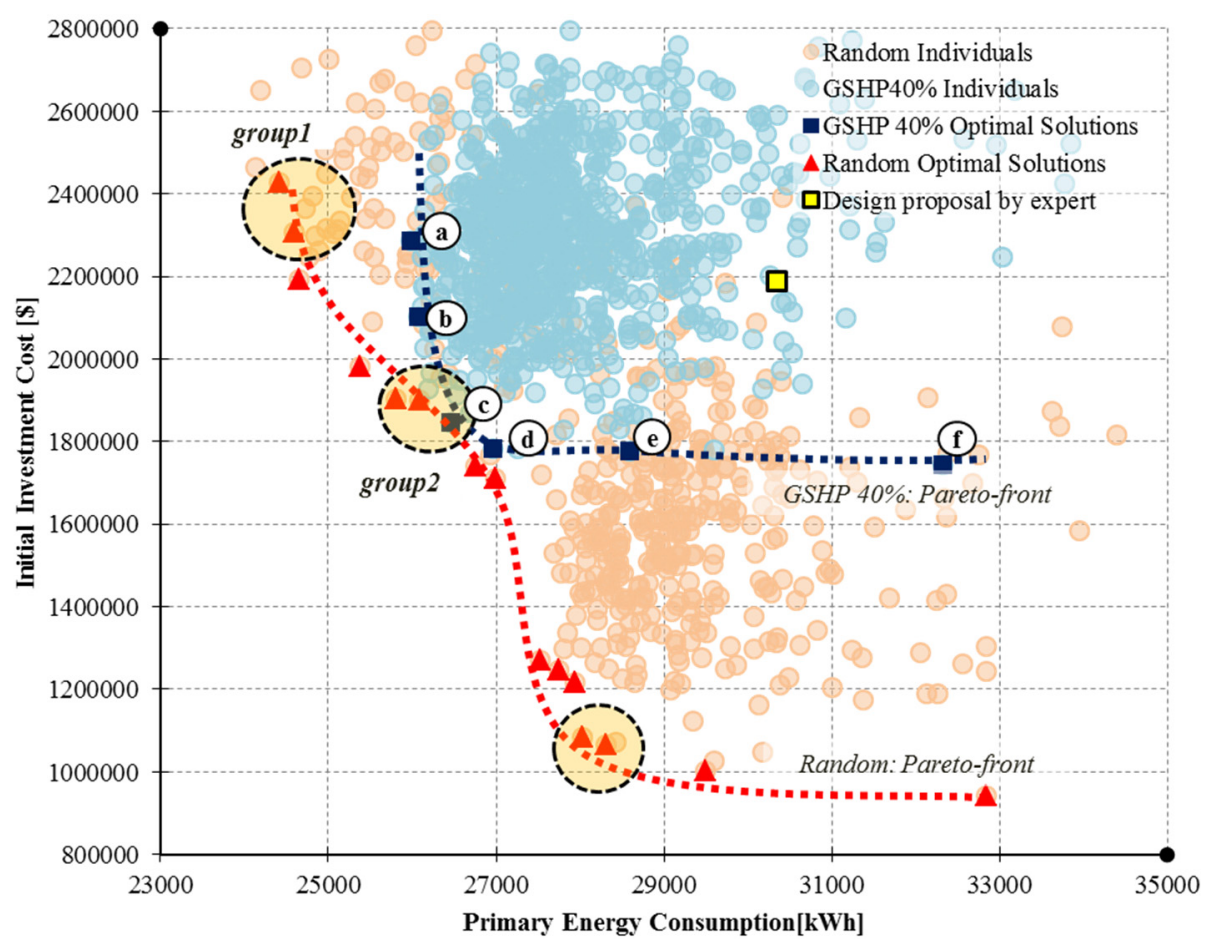

Figure 9. Pareto optimal solutions for Case Study 1 (comparison with GSHP 40\%).

Table 4. Optimization solutions of building 1 (GSHP 40\%).

\begin{tabular}{|c|c|c|c|c|c|c|c|c|}
\hline \multirow{2}{*}{ Device } & \multicolumn{8}{|c|}{ Solutions } \\
\hline & Capacity(kW) & Base & (a) & (b) & (C) & (d) & (e) & (f) \\
\hline \multirow{10}{*}{ Type } & TR1 & 0 & 700 & 0 & 0 & 700 & 1400 & 700 \\
\hline & TR2 & 0 & 1400 & 1400 & 1800 & 2700 & 0 & 1800 \\
\hline & TR3 & 0 & 1800 & 1050 & 700 & 0 & 0 & 1400 \\
\hline & AR1 & 1400 & 350 & 420 & 0 & 0 & 350 & 0 \\
\hline & AR2 & 1400 & 0 & 350 & 0 & 0 & 350 & 350 \\
\hline & GB1 & 1750 & 930 & 370 & 700 & 930 & 0 & 2250 \\
\hline & GB2 & 1750 & 115 & 700 & 930 & 115 & 1400 & 0 \\
\hline & CGS1 & 0 & 1750 & 1390 & 115 & 700 & 375 & 0 \\
\hline & CGS2 & 0 & 700 & 115 & 0 & 115 & 0 & 0 \\
\hline & GSHP & 1500 & 1200 & 1200 & 1200 & 1200 & 1200 & 1200 \\
\hline \multicolumn{2}{|c|}{ Initial Investment Cost $\left(\$ 10^{6}\right)$} & 2.21 & 2.31 & 2.12 & 1.86 & 1.80 & 1.79 & 1.76 \\
\hline \multicolumn{2}{|c|}{ Solution/Base (\%) } & - & 104 & 96 & 84 & 81 & 81 & 80 \\
\hline \multicolumn{2}{|c|}{ Primary Energy Consumption (kWh) } & 30,332 & 25,987 & 26,076 & 26,454 & 26,916 & 28,586 & 32,320 \\
\hline \multicolumn{2}{|c|}{ Solution/Base (\%) } & - & 86 & 86 & 87 & 89 & 94 & 107 \\
\hline
\end{tabular}

As shown in Figure 9, the results of Building 1 reveal that in the case with the constraints, the area of the alternative created by the optimization was placed at a higher position than the alternative created by random conditions. In the case of the GSHP, the energy efficiency is significant, but the initial investment cost is huge. Diverse optimal alternatives, as shown in Figure 9, are possible depending on the capacity. In this figure, the initial investment and the primary energy consumption are equal values of 1:1. In the case of (a), the initial investment and the primary energy consumption are less than the Base. Therefore, when comparing only the two indices, (a) can be a superior solution to Base. In case of 
the comparison of (a) and (f), the initial investment cost of (a) is more but the primary energy consumption is less than $(f$. However, the initial investment cost of $f($ is less but the primary energy consumption is more than (a). Therefore, these two solutions are in an equal relationship that cannot be superior to each other. Solutions of (a)-f) are all in this non-dominant relationship. 'GSHP40\% optimal solutions' shows the most optimal outcome in the case of GSHP $1200 \mathrm{~kW}$ use. However, this outcome does not mean the best choice. If the results are compared with the results of random optimization results could be more meaningful. Group 1, Group 2 and Group 3 show the results of the random optimization. The results may provide an output outside the given design condition. However, these results should be able to position the 'GSHP40\% optimal solutions' in the process of global optimization. Table 5 shows the configuration of optimal solution with random conditions. As shown in the figure, group1 has a similar investment cost as Solution (a), and GSHP 40\% has a similar investment cost as Solution (b); however, the optimal results were obtained under GSHP 50\%-60\%; thus, it may be more advantageous alternative to the energy consumption. Group 3 at the bottom indicates that the most advantageous energy system in terms of the initial investment cost is the one combining the TR, ACH, and GB as a global solution. Solutions (C) and (d) were obtained in the section where random conditions (Group 2) and GSHP $40 \%$ overlapped, indicating that the optimal solution, GSHP $40 \%$, as the globally optimal result consistent with the optimal result with the constraints.

Table 5. Optimization solutions of building 1 (Random).

\begin{tabular}{ccccccccc}
\hline \multirow{2}{*}{ Device } & \multicolumn{7}{c}{ Solutions } \\
\cline { 2 - 9 } & Capacity (kW) & Base & \multicolumn{2}{c}{ Group 1 } & Group 2 & \multicolumn{2}{c}{ Group 3 } \\
\hline TR1 & 0 & 1055 & 1055 & 3510 & 1400 & 1400 & 3510 \\
TR2 & 0 & 2700 & 1400 & 0 & 1055 & 1800 & 0 \\
TR3 & 0 & 0 & 1800 & 1055 & 0 & 700 & 700 \\
AR1 & 1400 & 0 & 985 & 0 & 420 & 740 & 530 \\
AR2 & 1400 & 350 & 0 & 420 & 350 & 350 & 350 \\
ACH & 0 & 1410 & 0 & 350 & 0 & 0 & 420 \\
GB1 & 1750 & 116 & 700 & 700 & 370 & 930 & 930 \\
Type & 1750 & 1395 & 930 & 700 & 700 & 700 & 930 \\
& GB2 & 0 & 374 & 374 & 116 & 370 & 1395 & 2245 \\
CGS1 & 0 & 0 & 0 & 0 & 374 & 0 & 0 \\
CGS2 & 0 & 0 & 0 & 0 & 0 & 116 & 0 \\
GSHP & 1500 & 1800 & 1500 & 1200 & 1200 & 0 & 0 \\
Initial Investment Cost (\$10 & 2.21 & 2.42 & 2.30 & 1.98 & 1.90 & 1.08 & 1.06 \\
Solution/Base (\%) & -- & 110 & 110 & 104 & 90 & 86 & 49 \\
Primary Energy Consumption $(\mathrm{kWh})$ & 30,332 & 24,422 & 24,594 & 25,378 & 25,801 & 28,022 & 28,305 \\
Solution/Base (\%) & -- & 81 & 81 & 84 & 85 & 92 & 93 \\
\hline
\end{tabular}

Therefore, it is regarded as the most suitable solution for decision making. Candidates for the optimal solution can be selected considering the operational patterns by the design-day. Figure 10 shows the energy supply patterns of Solutions (C) and (d). 

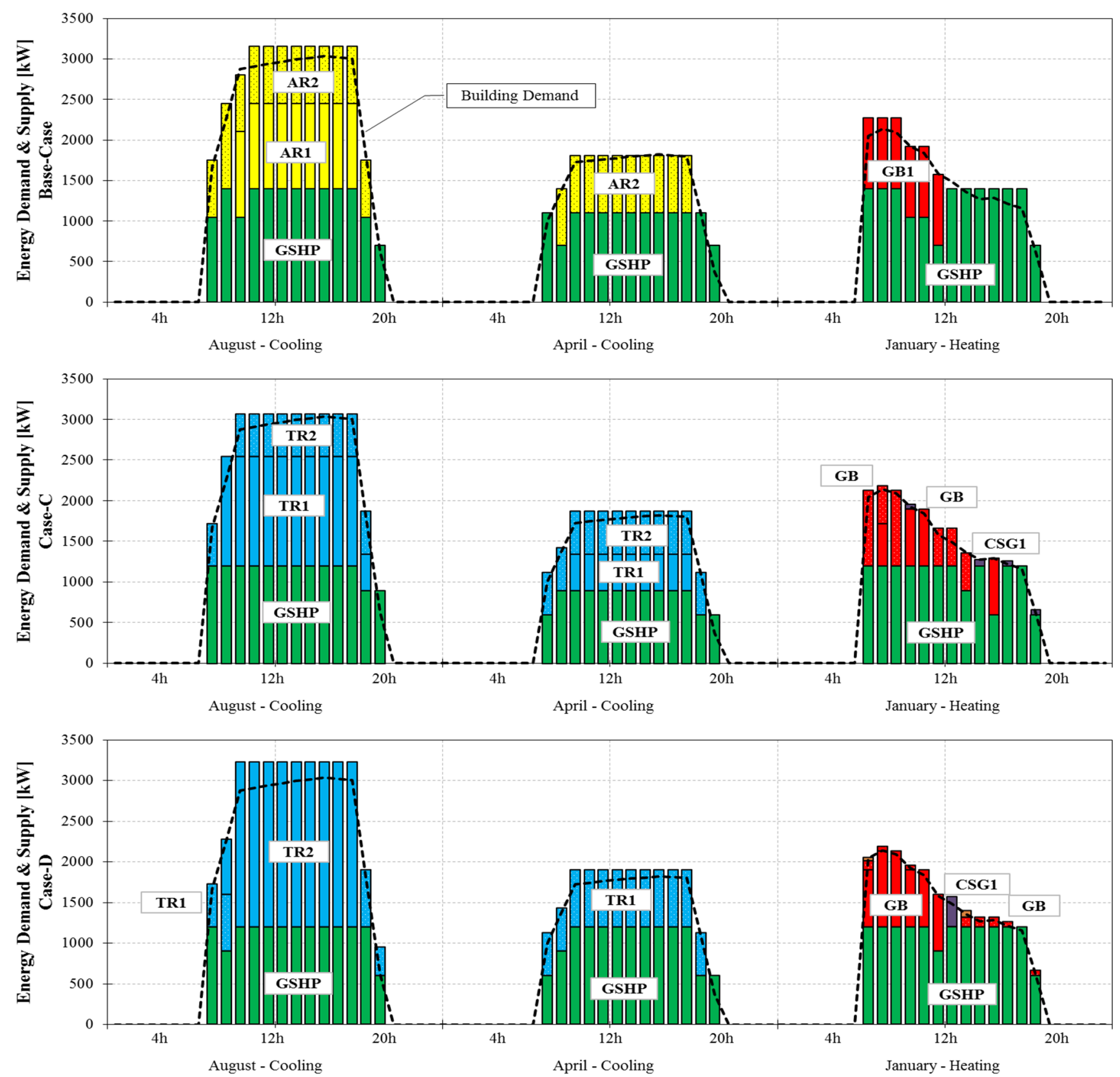

Figure 10. Building1: Cooling and heating supply operation by the optimal solutions.

Figure 11 shows the optimal results of Building 2, which is the case where ITS covers $40 \%$ of the peak cooling load. In the figure, the blue line represents the Pareto front of the case in which the ITS covers $40 \%$ of the building's peak cooling load; the red line shows the Pareto front of the case where $40 \%$ of the cooling peak load is covered by the combination of a gas-type cooling device with the ITS. The initial investment cost, primary energy use, energy system configuration, and optimization results of Building 2 are listed in Table 6. Table 7 shows the optimized solution in ITS $40 \%$ constraints.

As with Building 1, the energy system was configured in a variety of ways. In this case, nine Solutions (a)-(i) applicable to $59 \%-97 \%$ of the primary energy use range and $96 \%-273 \%$ of the initial investment cost range are provided as solutions. 
Table 6. Optimization solutions of building 2 (Gas + ITS).

\begin{tabular}{|c|c|c|c|c|c|c|c|c|c|c|}
\hline \multirow{2}{*}{ Device } & \multicolumn{10}{|c|}{ Solutions } \\
\hline & Capacity $(\mathrm{kW})$ & Base & (a) & (b) & (C) & (d) & (e) & (f) & (g) & (1) \\
\hline \multirow{10}{*}{ Type } & TR1 & 5100 & 1560 & 5100 & 3510 & 2280 & 1970 & 2780 & 2280 & 1970 \\
\hline & TR2 & 5100 & 2780 & 2780 & 2780 & 2780 & 2780 & 2780 & 2780 & 3510 \\
\hline & ITS & 51,000 & 27,800 & 27,800 & 27,800 & 27,800 & 27,800 & 27,800 & 27,800 & 35,100 \\
\hline & GSHP & 0 & 6259 & 4172 & 3129 & 2086 & 1043 & 1043 & 0 & 0 \\
\hline & AR1 & 0 & 0 & 0 & 0 & 0 & 1760 & 1580 & 1970 & 0 \\
\hline & AR2 & 0 & 1580 & 1970 & 1760 & 2460 & 1970 & 0 & 2460 & 2460 \\
\hline & GB1 & 5000 & 5000 & 2000 & 2000 & 2000 & 3760 & 3000 & 5000 & 2000 \\
\hline & GB2 & 5000 & 0 & 2480 & 2200 & 3000 & 3760 & 3760 & 3760 & 3760 \\
\hline & GB3 & 5000 & 2000 & 3000 & 2000 & 0 & 2000 & 5000 & 2480 & 2000 \\
\hline & GB4 & 5000 & 2480 & 2000 & 2480 & 4300 & 2200 & 4300 & 4300 & 4300 \\
\hline \multicolumn{2}{|c|}{$\begin{array}{l}\text { Initial Investment Cost } \\
\qquad\left(\$ 10^{6}\right)\end{array}$} & 1.28 & 3.50 & 3.37 & 3.03 & 2.68 & 2.55 & 2.28 & 1.73 & 1.42 \\
\hline \multicolumn{2}{|c|}{ Solution/Base (\%) } & - & 273 & 263 & 236 & 209 & 199 & 178 & 135 & 111 \\
\hline \multicolumn{2}{|c|}{$\begin{array}{c}\text { Primary Energy } \\
\text { Consumption }(\mathrm{kWh})\end{array}$} & 314,448 & 186,605 & 195,830 & 204,516 & 214,818 & 225,634 & 229,608 & 240,542 & 248,603 \\
\hline \multicolumn{2}{|c|}{ Solution/Base (\%) } & - & 59 & 62 & 65 & 68 & 72 & 73 & 76 & 79 \\
\hline
\end{tabular}

Table 7. Optimization solutions of building 2 (ITS40\%).

\begin{tabular}{|c|c|c|c|c|c|c|c|c|}
\hline \multirow{2}{*}{ Device } & \multicolumn{8}{|c|}{ Solutions } \\
\hline & Capacity(kW) & Base & (i) & (1) & (B) & (1) & (m) & (1) \\
\hline \multirow{10}{*}{ Type } & TR1 & 5100 & 1970 & 2280 & 0 & 0 & 0 & 0 \\
\hline & TR2 & 5100 & 5100 & 5100 & 5100 & 5100 & 5100 & 5100 \\
\hline & ITS & 51,000 & 51,000 & 51,000 & 51,000 & 51,000 & 51,000 & 51,000 \\
\hline & GSHP & 0 & 0 & 0 & 2086 & 2086 & 4172 & 3129 \\
\hline & AR1 & 0 & 0 & 1760 & 1760 & 3510 & 2460 & 3510 \\
\hline & AR2 & 0 & 0 & 3510 & 1580 & 1760 & 2810 & 2460 \\
\hline & GB1 & 5000 & 4300 & 4300 & 2480 & 2000 & 2200 & 0 \\
\hline & GB2 & 5000 & 4300 & 2000 & 2000 & 3760 & 2200 & 3760 \\
\hline & GB3 & 5000 & 4300 & 3000 & 2000 & 2480 & 3760 & 2200 \\
\hline & GB4 & 5000 & 2200 & 2480 & 2480 & 3760 & 2200 & 5000 \\
\hline \multicolumn{2}{|c|}{ Initial Investment Cost $\left(\$ 10^{6}\right)$} & 1.28 & 1.23 & 1.47 & 2.41 & 2.54 & 3.04 & 2.78 \\
\hline \multicolumn{2}{|c|}{ Solution/Base (\%) } & - & 96 & 115 & 188 & 198 & 238 & 217 \\
\hline \multicolumn{2}{|c|}{ Primary Energy Consumption (kWh) } & 314,448 & 304,022 & 287,045 & 266,402 & 261,705 & 251,252 & 251,761 \\
\hline \multicolumn{2}{|c|}{ Solution/Base (\%) } & - & 97 & 91 & 85 & 83 & 80 & 80 \\
\hline
\end{tabular}

As described in Section 2, when designing a cooling system in Korea, because the use of daytime electric demand up to $40 \%$ of the peak cooling load is permitted, non-daytime electrical energy system should be designed for the rest of capacity. In order to satisfy such conditions, the use of gas-type device such as AR, ACH or thermal storage system of ITS is essential. Therefore, the energy system of Building 2 must satisfy the condition of "(ITS $+\mathrm{AR}+\mathrm{ACH})>$ Peak Cooling Load $\times 0.6$ ". The optimization results of Building 2 (Figure 11) show that the use of the ITS reduces the initial investment cost, as in Solution (i), but poses a disadvantage in the primary energy use. The configuration of the energy system combined 
with the gas-type equipment, as in Solutions (g) (ITS 20\% + AR 20\%) and (h) (ITS 30\% + AR10\%), proves that an energy system that can reduce the primary energy use by $76 \%-79 \%$ with only an $11 \%$ increase in the initial investment cost was designed. The points on the dotted line are the solutions under the condition of ITS 40\% (Table 7), but they are dominated by Solutions (a)-(h), with the mixed use of gas device, indicating that for the configuration of the energy system. Solutions (a)-(i) are the optimal values having lowest initial investment cost and energy consumption. Therefore, this study confirms that building energy system design using the multiobjective optimization can offer the optimal alternatives to the design of a complex energy system in which diverse combinations can be generated.

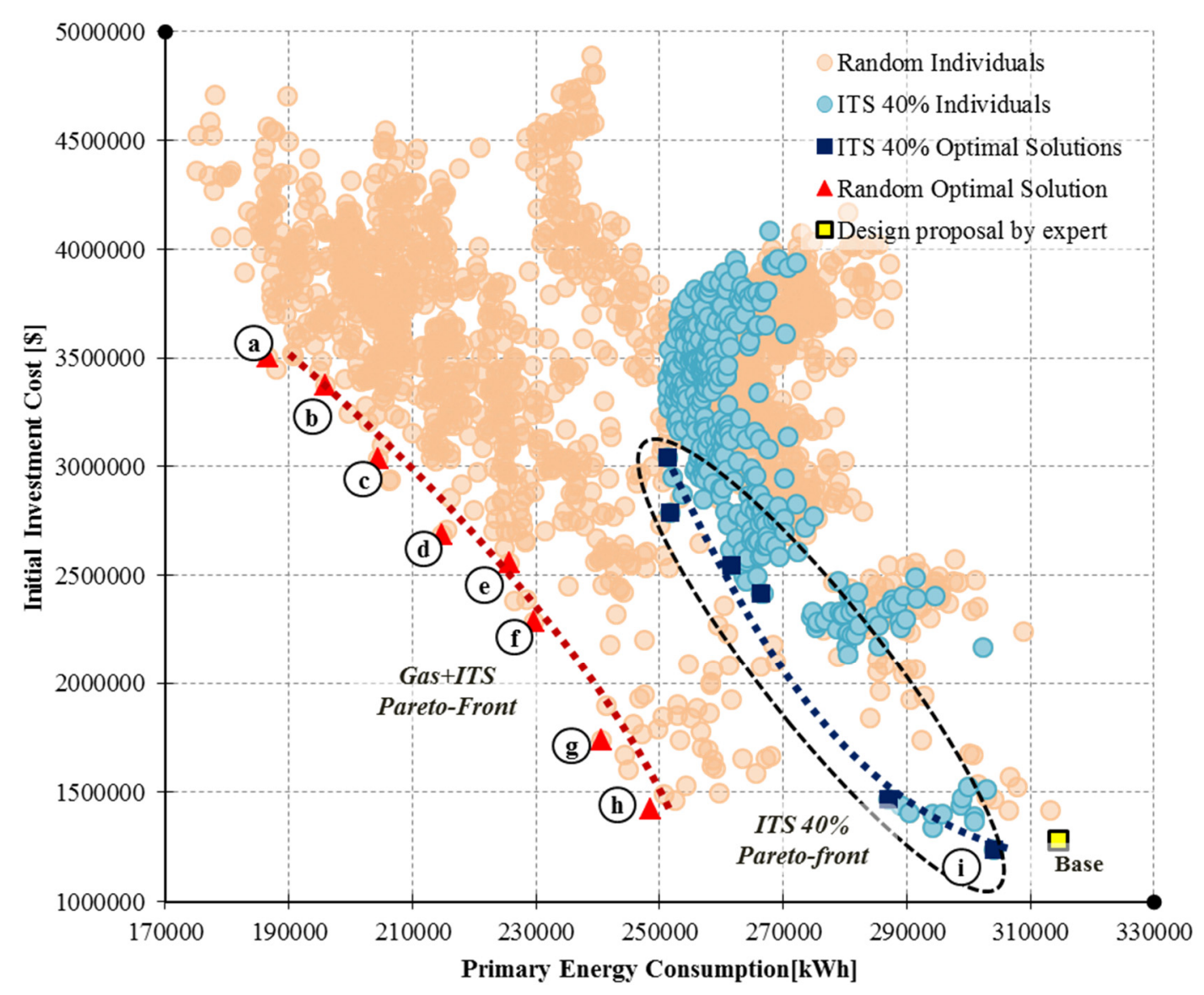

Figure 11. Pareto optimal solutions for case study 2 (comparison with ITS 40\%).

\section{Conclusions and Future Directions}

In this study, a method for calculating the types and capacities of the devices that minimize the initial investment cost and primary energy use was proposed for building the energy system design. Moreover, the applicability of the proposed method was verified by a case study involving two buildings in the design phase. This study has the following conclusions:

(1) The energy system minimizing the primary energy use and initial investment cost was derived by the energy consumption according to the combination of energy systems or devices. It was calculated using the regression model created by the survey and based on the performance curve, indicating the mechanical characteristics of the device, heating and cooling load profiles by the design-day, information in the early design stage, and initial investment cost. 
(2) The applicability and usability of the proposed method were verified by the case studies, and various optimal design alternatives were analyzed using the Pareto-based analysis method. As a result, it was confirmed that the proposed method could provide optimal solutions for the design of a complex energy system.

(3) The proposed method is capable of supporting the decision-making process by providing various design alternatives with optimal designs reflecting the intentions of the clients and engineers, and capable of maximizing the energy and cost efficiency in the long term.

In this study, only the primary energy use and initial investment cost were accounted as decision-making factors. For the future direction, studies reflecting various other indices such as the energy cost, lifecycle cost, thermal comport, and carbon emission in the energy system design will be performed.

\section{Acknowledgments}

This research was supported by a grant (11 Urban Architecture G02) from Urban Architecture Program funded by the Ministry of Land, Transport, and Maritime Affairs of the South Korean government.

\section{Author Contributions}

The author Dong-Seok Kong developed the methodology, performed the simulation-optimization and wrote the full manuscript. The authors Yong-Sung Jang discussed the results and implications at all stages. Jung-Ho Huh advised all tasks, double-checked the results and the whole manuscript. All authors proof read the paper.

\section{Conflicts of Interest}

The authors declare no conflict of interest.

\section{Acronyms}

$\begin{array}{ll}\text { TR } & \text { Turbo refrigerator } \\ \text { AR } & \text { Absorption refrigerator } \\ \text { ACH } & \text { Absorption chiller \& heater } \\ \text { HP } & \text { Heat pump } \\ \text { GB } & \text { Gas boiler } \\ \text { CHP } & \text { Cogeneration heat \& power system } \\ \text { ITS } & \text { Ice thermal storage system } \\ \text { WTS } & \text { Water thermal storage system } \\ \text { GSHP } & \text { Geothermal heat pump } \\ \text { PV } & \text { Photovoltaic system } \\ \text { Solar } & \text { Solar thermal system } \\ \text { PLR } & \text { Partial load ratio }\end{array}$




\section{References}

1. Djunaedy, E.; van den Wymelenberg, K.; Acker, B.; Thimmana, H. Oversizing of HVAC system: Signatures and penalties. Energy Build. 2011, 43, 468-475.

2. Jacobs, P.; Henderson, H. State-of-the-Art Review Whole Building, Building Envelope, and HVAC Component and System Simulation and Design Tools; Architectural Energy Corporation: Boulder, CO, USA, 2002.

3. Shahrestani, M.; Yao, R.; Cook, G.K. Characterizing the energy performance of centralized HVAC \& R systems in the UK. Energy Build. 2013, 62, 239-247.

4. Hafez, O.; Bhattacharya, K. Optimal planning and design of a renewable energy based supply system for microgrids. Renew. Energy 2012, 45, 7-15.

5. Kayo, G.; Ooka, R. Building energy system optimizations with utilization of waste heat from cogenerations by means of genetic algorithm. Energy Build. 2010, 42, 985-991.

6. Kayo, G.; Ooka, R. Optimal design method for distributed energy system using genetic algorithm: Examining the influence of GA parameters on the accuracy of calculation results estimated by the optimal design method and confirming the applicability of designing distributed energy system. J. Environ. Eng. Trans. Archit. Inst. Jpn. 2009, 74, 869-876. (In Japanese)

7. Ooka, R.; Komamura, K. Optimal design method for building energy systems using genetic algorithms. Build. Environ. 2009, 44, 1538-1544.

8. Seo, J.; Ooka, R.; Kim, J.T.; Nam, Y. Optimization of the HVAC system design to minimize primary energy demand. Energy Build. 2014, 76, 102-108.

9. Shaneb, O.A.; Coates, G.; Taylor, P.C. Sizing of residential $\mu$ CHP systems. Energy Build. 2011, 43, 1991-2001.

10. Harris, J.; Anderson, J.; Shafron, W. Investment in energy efficiency: A survey of Australian firms. Energy Policy 2000, 28, 867-876.

11. Kayo, G.; Ooka, R. Multi-objective genetic algorithm optimized for energy consumption and cost in building energy system design. J. Environ. Eng. Trans. Archit. Inst. Jpn. 2010, 75, 735-740. (In Japanese)

12. Malatji, E.M.; Zhang, J.; Xia, X. A multiple objective optimisation model for building energy efficiency investment decision. Energy Build. 2013, 61, 81-87.

13. Fazlollahi, S.; Mandel, P.; Becker, G.; Maréchal, F. Methods for multi-objective investment and operating optimization of complex energy systems. Energy 2012, 45, 12-22.

14. Srinivas, N.; Deb, K. Muiltiobjective optimization using nondominated sorting in genetic algorithms. Evol. Comput. 1994, 2, 221-248.

15. Deb, K.; Pratap, A.; Agarwal, S.; Meyarivan, T.A.M.T. A fast and elitist multiobjective genetic algorithm: NSGA-II. IEEE Trans. Evol Comput 2002, 6, 182-197.

16. Burdick, A. Strategy Guideline: HVAC Equipment Sizing; US Department of Energy: Washington, DC, USA, 2012.

17. Pérez-Lombard, L.; Ortiz, J.; Coronel, J.F.; Maestre, I.R. A review of HVAC systems requirements in building energy regulations. Energy Build. 2011, 43, 255-268. 
18. American Society of Heating, Refrigerating and Air-Conditioning Engineers (ASHRAE). Non-residential cooling and heating load calculations. In ASHRAE Handbook-Fundamentals; American Society of Heating, Refrigerating and Air-Conditioning Engineers: Atlanta, GA, USA, 2009; Chapter 28.

19. Elkhuizen, P.A.; Peitsman, H.C.; Wienk, W.J. A new design guideline for the heating and cooling curve in AHU units of HVAC systems. Build. Serv. Eng. Res. Technol. 2003, 24, 191-202.

20. Attia, S.; Hamdy, M.; O’Brien, W.; Carlucci, S. Assessing gaps and needs for integrating building performance optimization tools in net zero energy buildings design. Energy Build. 2013, 60, 110-124.

21. Gossard, D.; Lartigue, B.; Thellier, F. Multi-objective optimization of a building envelope for thermal performance using genetic algorithms and artificial neural network. Energy Build. 2013, 67, 253-260.

22. Hamdy, M.; Hasan, A.; Siren, K. A multi-stage optimization method for cost-optimal and nearly-zero-energy building solutions in line with the EPBD-recast 2010. Energy Build. 2013, 56, 189-203.

23. United States Department of Energy (USDOE). EnergyPlus Engineering Reference-The Reference to EnergyPlus Calculations; USDOE: Washington, DC, USA, 2013.

24. Korea Energy Management Corporation Home Page. Available online: http://www.kemco.or.kr (accessed on 18 May 2015).

25. Korea Price Information Home Page. Available online: http://www.kpi.or.kr (accessed on 18 May 2015).

26. Woradechjumroen, D.; Yu, Y.; Li, H.; Yu, D.; Yang, H. Analysis of HVAC system oversizing in commercial buildings through field measurements. Energy Build. 2014, 69, 131-143.

(C) 2015 by the authors; licensee MDPI, Basel, Switzerland. This article is an open access article distributed under the terms and conditions of the Creative Commons Attribution license (http://creativecommons.org/licenses/by/4.0/). 